\title{
Taste preferences measured by tongue licks and bar presses as a function of age in the rat'
}

DOUGLAS W. BLOOMQUIST ${ }^{2}$ AND DOUGLAS K. CANDLAND

BUCKNELL UNIVERSITY

\begin{abstract}
Abstraet
Rats of 40,150 , or 300 days, $N=46$, were deprived of water daily for 15-hr. Number of tongue licks or bar presses during daily $30-\mathrm{min}$. tests for water, sucrose, quinine, salt, or hydrochloric acid at presumed preference threshold concentrations were recorded. Significant differences between performance and drinking measures of preference were found for quinine at all ages, but not for other solutions.
\end{abstract}

\section{Problem}

Although amount of intake and number of tongue licks have been the most common measures of taste preference in animal Ss, studies which have used instrumental procedures (Guttman, 1953) have shown such procedures to be useful. However, intake measures have not been compared directly with performance measures. Moreover, although evidence from human Ss suggests differences in preference as a function of age (Laird \& Breen, 1939; Richter \& Campbell, 1940), similar results have not been observed in rats (Wagner, 1965) for sugar. The purpose of the present study was to investigate relative preference as a function of (1) an operant response versus simple intake and (2) age.

\section{Method}

The Ss were 46 albino rats, 21 males and 25 females, of Carworth Farms CFE strain which were bred and raised in the Bucknell University colony. The Ss were assigned to three age groups at the onset of testing: 40 days, $\mathrm{N}=16 ; 150$ days, $\mathrm{N}=16 ; 300$ days, $\mathrm{N}=14$. The Ss lived in individual cages ( 7 by 7 by 10 in) during the training and testing stages of the experiment. A diet of Purina Lab Chow was available ad lib., although tap water was available for only 6-hr. daily during the experiment.

Conditioning chambers (Model 1107, Foringer) equipped with liquid feeders and $0.1 \mathrm{cc}$ liquid reinforcement cups were used to assess preference by an operant measure. For groups in which tongue licks in a free drinking situation were recorded, hanging type cages were insulated from the rack. A clear Plexiglas panel $1 / 8$ in thick covered the interior. A $3 / 8$ in hole in the panel permitted Ss to extend their tongues to drink from a glass drinking tube fitted into a glass test tube which accommodated a No. 7 rubber stopper. The test tube was mounted on the cages at approximately a $45^{\circ}$ angle in order to reduce the amount of dripping from the tube. Tongue licks were detected by Grason Stadler Drinkometers (Model E4690A). The drinking tube was recessed $1 / 4$ in to prevent closing of the circuit when $\mathrm{S}$ touched the tube with his nose or mouth while licking.
One concentration for each solution was selected based on those reported for $75 \%$ preference (or 25\% aversion). The sucrose concentration was from Burright \& Kappauf (1963) and quinine from Young et al (1963). Concentration for both salt and hydrochloric acid were interpolated from Pfaffman's (1957) data. The concentrations were as follows: sucrose (CHO), $0.0093 \mathrm{M}$; quinine (QHC1), $0.000238 \mathrm{M}$; salt $(\mathrm{NaC} 1), 0.0642 \mathrm{M}$; and acid ( $\mathrm{HC} 1), 0.00178 \mathrm{M}$.

A 3 (Age) by 2 (Measure) by 4 (Solutions) factorial design on repeated measures was employed for six independent groups. Eight Ss, four of each sex, were assigned to the 40 and 150 day old groups. Each of the 300 day groups contained three males and four females. Bar pressing training to a VI30-sec. schedule was initiated approximately 15 days before the onset of testing. After Ss responded steadily to the schedule, they were allowed ad lib. water in the home cage for 4-6 days, depending on age, weight, and amount of deprivation during training, to permit them to re-acquire normal weight before testing. Less training was required for the drinking (tongue licks) groups, since drinking from a tube was a familiar response.

Although preference was assessed by two different methods, the general experimental procedure was similar for all groups. The procedure was a modification of the Weiner \& Stellar (1951) single stimulus method. In the present study, Ss were deprived of water daily for $15-\mathrm{hr}$. in order to insure ready responding during the $30-\mathrm{min}$. test period and to control the motivation over days. Following the test period, Ss were not permitted water for $2.5 \mathrm{hr}$., after which tap water was available freely for 6-hr. There was little variation in weight change over days for older Ss; however, 40 day Ss gained 4-5 gm each day.

Testing for each $\mathrm{S}$ lasted between 14 and 20 days, depending on the number of trials required for stable daily responding to distilled water before taste solutions were presented. When testing began under the restricted water schedule, Ss were presented distilled water in the appropriate apparatus for a minimum of four consecutive days. When $\mathrm{Ss}^{\prime}$ responding (tongue licks or bar presses) was stable for at least two consecutive days, they were systematically presented different taste solutions, each for two consecutive days, during the next eight trials. In general, stable responding to distilled water occurred sooner in the drinking groups than in bar pressing groups. For counterbalancing purposes, two Ss in each group began testing with a different solution and this procedure was followed for succeeding 
solutions to partially balance the effects of cumulative experience with solutions. Solutions presumed to be similarly preferred (sucrose and salt) and similarly nonpreferred (quinine and acid) were presented alternately. Distilled water was presented again for two days following trials on solutions.

\section{Results and Discussion}

Response percentages, defined as the ratio of mean number of responses for each solution (two days) over the mean number of responses to distilled water (four days - two pre- and two post-solution trials) by 100.0, and ranges are presented in Fig. 1. These data are treated by an analysis of variance employing the model for a three-factor experiment with repeated measures described by Winer (1962). As expected, the solution factor was significant $(F=92.15 ; d f=3,120 ; p<.01)$, indicating that solutions were differentially preferred from one another. Salt is preferred while quinine is not preferred regardless of the measure of preference or age. No significant preference for sucrose or aversion for acid is evident, however, and it appears that the concentrations for these two solutions were not sufficiently above threshold for a preference or aversion to water to be demonstrated.

The other significant source of variance was Measure by Solutions $(F=7.66 ; \mathrm{df}=3,120 ; \mathrm{p}<.01)$ showing that there is significant disagreement between measures on one or more solutions. Further statistical analysis showed that the performance and drinking measures of preference differed significantly $(p<.05)$ on quinine at all ages and on salt by 300 day Ss. The age factor was not significant.

Figure 2 shows a general agreement between the two

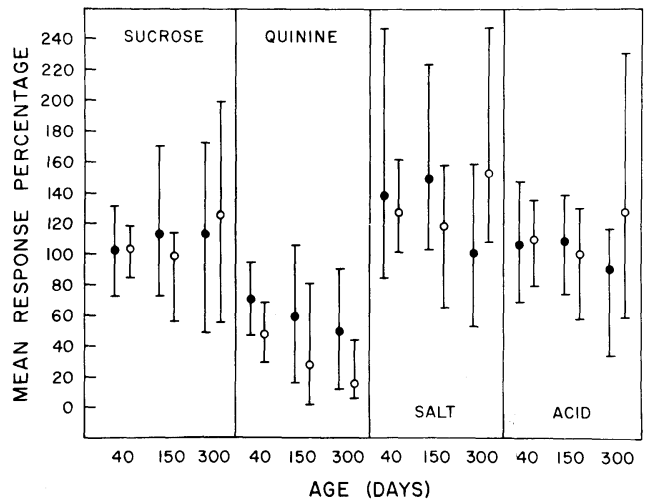

Fig. 1. Mean response percentages and ranges to the four solutions as a function of age and measure. Closed circles represent bar pressing; open circles represent tongue licks.

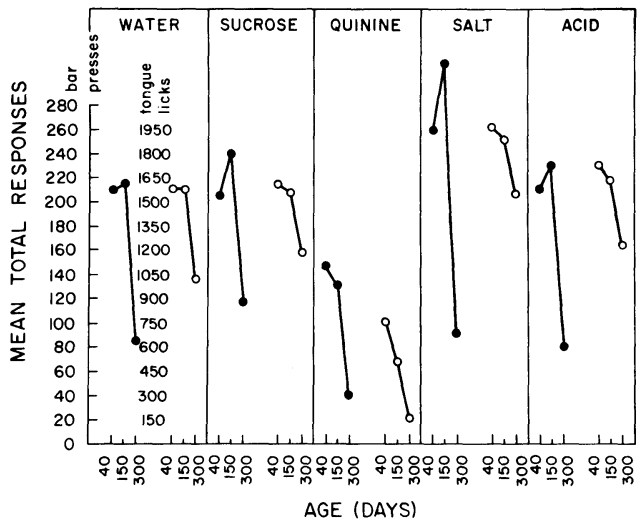

Fig. 2. Mean total bar presses or tongue licks to solutions and water as a function of age.

measures of intake as a function of age. In all cases, older (300 day) Ss make fewer responses than younger Ss (40 and 150). This probably reflects differential motivation provided by a $15-\mathrm{hr}$. deprivation period.

In summary, age differences do appear, but do not reach statistical significance. There is reasonably close agreement, except for quinine intake, between bar pressing and licking.

\section{References}

Burright, R. G., \& Kappauf, W. E. Preference threshold of the white rat for sucrose. J. comp. physiol. Psychol., 1963, 56, 171-173.

Guttman, N. Operant conditioning, extinction and periodic reinforcement in relation to concentration of sucrose used as reinforcing agent. J. exp. Psychol., 1953, 46, 213-224.

Laird, D. A., \& Breen, W. J. Sex and age alterations in taste preferences.. J. Amer. diet. Ass., 1939, 15, 549-550.

Pfaffman, C. The sensory and motivating properties of the sence of taste. In Nebraska Symposium on Motivation, 1961, 71-108.

Richter, C. P., \& Campbell, K. H. Sucrose taste thresholds of rats and humans. Amer. J. Physiol., 1940, 128, 291-297.

Wagner, M. W. The effects of age, weight and experience on relative sugar preference in the albino rat. Psychon. Sci., 1965, 2, 243-244.

Weiner, I. H., \& Stellar, E. Salt preference of the rat determined by a single stimulus method. J. comp. physiol. Psychol., 1951, $44,394-401$.

Winer, B. J. Statistical principles in experimental design. New York: McGraw-Hill, 1962.

Young, P. T., Burright, R. G., \& Tromater, J. Preferences of the white rat for solutions of sucrose and quinine hydrochloride. Amer. J. Psychol., 1963, 76, 205-217.

Notes

1. The first author conducted this research in partial fulfillment of the requirements for the degree of Master of Arts at Bucknell University. Research was supported by grant MH 06988-02 from the U. S. Public Health Service to the second author.

2. Now at Michigan State University. 